\title{
Avaliação da eficácia dos CRITÉRIOS de ReCEBIMENTO DE EFLUENTES NÃO DOMÉSTICOS EM SISTEMAS DE COLETA E transporte de esgotos sanitários em São Paulo
}

\section{EFFECTIVENESS OF ACCEPTANCE STANDARDS OF NON-HOUSEHOLD EFFLUENTS to SÃo PAulo State PUbliCly OWNED TREATMENT WORKS}

\author{
IRINEU DELATORRE JUNIOR
}

Tecnólogo em Obras Hidráulicas. Mestre em Engenharia Civil, área Engenharia Hidráulica: opção Saneamento Básico pela Escola Politécnic a da Universidade de São Paulo

\begin{abstract}
DiONE MARI MORITA
Doutora em Engenharia Hidráulica e Sanitária pela Universidade de São Paulo. Professora do Departamento de Engenharia Hidráulica e Sanitária da Escola Politécnica da Universidade de São Paulo
\end{abstract}

Recebido:13/03/06 Aceito: 21/01/07

\section{RESUMO}

No presente trabalho, foram correlacionadas características de efluentes não domésticos, lançados no sistema de esgotos sanitários da Região Metropolitana de São Paulo (SESRMSP), com os dados de manutenção. Foram também realizadas medições do limite inferior de explosividade e de concentrações de sulfetos nos principais coletores-tronco e interceptores deste sistema. Dos resultados obtidos, concluiuse que: os critérios atuais de recebimento de efluentes não domésticos no SES-RMSP, no que se refere às interferências físicas e operacionais, não são eficazes; para a análise da possiblidade de recebimento, devem ser levados em consideração as matérias-primas, produtos auxiliares e fluxogramas do processo produtivo; deve haver comunicação entre as diversas áreas envolvidas na operação do SES-RMSP e a concessionária deve fazer o monitoramento sistemático do limite inferior de explosividade.

PALAVRAS-CHAVE: Efluentes não domésticos, sistema de coleta e transporte de esgotos, interferências físicas e operacionais, legislação ambiental.

\section{INTRODUÇÃO}

Os programas de saneamento em municípios industrializados devem contemplar o controle dos lançamentos de águas residuárias com características não domésticas, pois as mesmas transportam poluentes que provocam interferências físicas e operacionais no sistema de esgotamento sanitário (SES).

Garantir a integridade física dos sistemas de coleta e transporte de esgotos de um determinado município é preservar o patrimônio público investido em obras de saneamento, assim

\section{ABSTRACT}

In this research work, some characteristics of non-household effluents which are conveyed into the sanitary sewerage system of São Paulo's Metropolitan Region (SPMR's Sewerage System) were correlated to maintenance data. Measurements of inferior limit of explosion and sulfide concentrations in the sewage mains and interceptor lines were also conducted. The results led us to conclude that the current non-domestic effluent collection criteria in SPMR's Severage System are not effective with regard to physical and operational interferences. Auxiliary products, raw materials and the production process flux itself must be taken into consideration in the analysis made to evaluate whether or not such effluents can be conveyed into the Severage System. There must be communication among the sectors involved in the operation of SPMR's Sewerage System and the responsible Sewerage Company in charge should monitor the inferior limit of explosion at all times.

KEYWORDS: Non-household effluents, publicly owned treatment works, sewerage system, environmental legislation. como garantir a saúde dos operadores do SES é obrigação das concessionárias de saneamento.

As interferências físicas mais freqüentes são as que comprometem o bom funcionamento do SES, tais como rompimento de coletores, devido à corrosão, e diminuição da seção, por causa do assoreamento e incrustação. Esses problemas estão associados ao lançamento de efluentes ácidos ou alcalinos, contendo sulfetos e sulfatos, óleos e graxas e também por excesso de sólidos sedimentáveis.

Os operadores estão diretamente expostos aos poluentes lançados no
SES. Alguns podem conter substâncias tóxicas e inflamáveis, provocando efeitos agudos e até mesmo crônicos nos operadores. Estudos realizados por companhias de saneamento internacionais têm demonstrado associação entre o lançamento de efluentes não domésticos (ENDs) e casos de irritação na pele, cefaléias, edemas pulmonares e até morte em operadores A presença desses poluentes associados a despejos com altas temperaturas pode agravar o problema.

Foi pensando nos problemas expostos anteriormente que agências ambientais e concessionárias de saneamento de 
diversos países passaram a se preocupar com o controle do lançamento de ENDs no sistema público de esgotos.

A Agência de Proteção Ambiental Norte-Americana (USEPA) tem elaborado manuais de orientação para o controle de lançamentos de ENDs em SES, sendo este baseado no estabelecimento de descargas proibidas, de limites para poluentes específicos, na redução de toxicidade e em programas de pré-tratamento. Outros países como Itália, Canadá, Porto Rico, Chile e Eslováquia passaram a adotar práticas de recebimento baseadas no modelo norte-americano.

A nível nacional, foi elaborada a norma NBR 9.800 (ABNT, 1987), baseada no artigo 19A do Decreto 15.425/80 do Estado de São Paulo, CETESB (1995) que por sua vez, seguiu os princípios norte-americanos. Minas Gerais, Rio Grande do Sul e Paraná também adotaram a referida norma.

A necessidade de uma avaliação mais criteriosa dos parâmetros de recebimento de ENDs no sistema de coleta e transporte de esgotos sanitários adotados no Brasil e, principalmente, no Estado de São Paulo, que foi o pioneiro, está diretamente ligada aos problemas de corrosão, inflamabilidade, explosividade e obstruçôes por incrustação, entre outros. A legislação paulista, em uso desde 1980, necessita de uma avaliação de sua eficácia e possivelmente de modernização e para isso, o conhecimento de ocorrências passadas é imprescindível. Alguns limites podem estar muito restritivo, assim como outros muito permissivos, inviabilizando o recebimento de alguns efluentes ou a aceitação de outros que, mesmo obedecendo a legislação, causam danos ao sistema.

\section{MATERIAL E MÉTODOS}

\section{Interferências físicas e operacionais no SES}

A diversidade de ramos de atividade encontradas nas grandes metrópoles, a princípio, inviabiliza uma caracterização completa e um conhecimento detalhado de todo o universo de indústrias e serviços que possam gerar efluentes e que estejam conectados ao sistema.

Em 2003, a CETESB possuía cadastradas 670 empresas ativas na RMSP, que foram consideradas prioritárias para o Projeto Tietê fase I. Deste cadastro, foram escolhidos, no presente trabalho, os ramos de atividades geradores de efluentes que pudessem provocar impactos na operação e manutenção do sistema de coleta e transporte de esgotos segundo Kienow \& Kienow (2005), ESTADOS UNIDOS (2002), Tsutiya \& Além Sobrinho (2000), EPA (1986), Morita (1993), EPA (1995a e b), WEF (1994). As interferências causadas por incrustação, corrosão e obstrução têm como causas o lançamento de efluentes contendo sulfatos e sulfetos; $\mathrm{pH}$ fora da faixa de 6,0 a 10,0; excesso de óleos e graxas e sólidos sedimentáveis. Dessa forma, após a escolha dos ramos de atividade, numa consulta e análise de mais de 300 Relatórios de Caracterização de Efluentes Não Domésticos, elaborados pela CETESB entre os anos de 1997 e 1999, selecionaram-se as empresas que possuíam essas características em seus efluentes. Através da análise dos produtos, das matérias-primas e dos produtos auxiliares utilizados no processo industrial, além das vazões domésticas e industriais, foram catalogados 129 relatórios e 174 laudos de caracterização dos ENDs. Para facilitar a análise dos resultados, gerou-se um banco de dados em Access 2000, que detalha as informaçôes cadastrais.

Para correlacionar tais lançamentos com as interferências físicas na rede coletora de esgotos (RCE), foi feito o cruzamento dos endereços de cada empresa (do banco de dados cadastrais) com as informações sobre as manutenções realizadas nas redes coletoras de esgotos nesses logradouros, obtidas da concessionária de saneamento local, que disponibilizou um banco de dados em Excel, contendo 426.460 ocorrências, entre os anos de 2002 e 2005 . Correlacionados esses dois bancos de dados, foram analisadas as características dos efluentes lançados e as seguintes informaçōes sobre o processo industrial: produto fabricado; matéria-prima; produtos auxiliares; origem dos efluentes, vazões doméstica e industrial.

Para melhor avaliar as interferências operacionais provocadas pelo lançamento de despejos contendo óleos e graxas, sulfatos e sulfetos, realizou-se uma pesquisa nos arquivos de vídeo filmagem da empresa VIDEOSAN SANEAMENTO INSTRUMENTAL LTDA, constantes de 28 relatórios fotográficos de Inspeção Por Circuito Fechado de TV. Tais arquivos apresen- tam as seguintes informações: data do relatório; número da bacia de esgotamento; local; trecho; profundidade do coletor tipo de seção, diâmetro e material da tubulação; extensão total e inspecionada. Os dados desses relatórios foram confrontados com as informações sobre as manutenções citadas anteriormente.

\section{Explosividade e inflamabilidade no SES}

Para avaliar o risco de explosividade e inflamabilidade, foram realizadas mediçôes em campo em 27 pontos da RCE, utilizando dois equipamentos: um monitor portátil detector de inflamável, modelo Minigás 4, marca Neotronics, que mede quatro parâmetros citados a seguir, simultaneamente, e um oxi-explosímetro, modelo Safe Check 200, da marca Quest: milhão;

- Gás sulfídrico em partes por

- Teor de oxigênio em porcentagem;

- Limite inferior de explosividade em porcentagem.

- Monóxido de carbono em partes por milhão.

Correlacionaram-se, também, os dados do processo industrial com as características do efluente e essas mediçôes de campo. Além disso, realizou-se uma pesquisa nos atendimentos de emergência executados pelo Setor de Operaçôes de Emergência do órgão ambiental estadual. Esse setor tem por finalidade intervir em situaçôes emergenciais que representam riscos ao meio ambiente, causados por eventos acidentais ocorridos em fontes que manipulam substâncias químicas no Estado de São Paulo, nas mais diversas atividades, destacando-se os transportes rodoviários, marítimos e postos de abastecimento. Neste último caso, normalmente a denúncia parte do usuário do SES, que, de alguma forma, percebe odor de gasolina ou qualquer outro combustível dentro do seu imóvel. Após receberem a denúncia, técnicos vão ao local para iniciar a avaliação das condiçõos presentes e uma das atividades é monitorar o LIE na RCE. Esse monitoramento é descrito no Registro de Acidente Ambiental.

No presente trabalho, foram pesquisados 44 registros, de 1998 a 2004 , destacando-se os acidentes nos quais houve infiltração de combustíveis na RCE. 


\section{$\mathrm{pH}$, temperatura e concentrações de sulfato e sulfeto no esgoto sanitário da RMSP}

A fim de conhecer as características dos esgotos que fluem no SES, quanto aos parâmetros sulfato, sulfeto, $\mathrm{pH}$ e temperatura, foram realizadas coletas em 49 pontos. A escolha desses pontos levou em conta a representatividade da contribuição, ou seja, foram selecionados coletores que atendem toda uma bacia de esgotamento onde existem indústrias, comércio e predominância de residências. Outra condição foi escolher coletores que estavam conectados a um interceptor que transporta os esgotos para uma ETE. As amostras foram coletadas, preservadas e analisadas conforme APHA; AWWA; WEF (1998). Além das coletas realizadas, foram pesquisados, junto às empresas de saneamento, caracterizações de esgotos realizadas no SES.

\section{APRESENTACÃO E DISCUSSÃO DOS RESULTADOS}

\section{Interferências físicas e operacionais no SES}

A verificação das interferências físicas e operacionais, quanto à incrus- tação, foi baseada na associação dos dados de caracterização dos efluentes lançados pelas empresas, constantes do banco de dados Access, elaborado através dos relatórios de caracterização, com as manutenções realizadas na RCE entre os anos de 2002 e 2005 do banco de dados da companhia de saneamento. Para um melhor entendimento e visualização desses dados, foram elaboradas tabelas sínteses, onde constam todas as informaçôes de interesse. Uma tabela síntese típica é apresentada a seguir (Tabela 1).

Ao elaborar as tabelas síntese, verificou-se a necessidade de comparar dados de uma rua onde a RCE recebia diretamente os efluentes gerados de uma determinada empresa e uma outra na qual, teoricamente, não havia nenhum lançamento que pudesse causar freqüentes manutenções. Para isso, foram selecionadas ruas situadas à montante e à jusante da RCE objeto da investigação. Porém, ao se adotar tal procedimento, observou-se que algumas ruas à montante e à jusante também apresentavam manutenções freqüentes. Pesquisou-se, então, a causa de tal ocorrência, chegando à conclusão descrita a seguir.

Atualmente, as empresas de saneamento têm investido muito em novos equipamentos para manutenção de
RCE, tais como desobstruções, lavagens e limpezas de RCE e poço de visita PV, sendo que não há mais a necessidade que operadores adentrem nos espaços confinados.

Para desobstruções e lavagens de RCE, normalmente, utiliza-se equipamento de alta pressão para limpeza hidrodinâmica ("Sewer Jet"). Tal equipamento é constituído por um caminhão com um tanque contendo água sob pressão, de onde parte uma mangueira com um jato em sua extremidade. Essa mangueira é introduzida através de um PV e direcionada à montante do ponto obstruído. A potência do jato vai conduzindo o material para jusante, justificando as freqüentes manutenções nesta direção. As interferências observadas na RCE das ruas situadas à montante do lançamento são facilmente explicáveis. Quando há uma obstrução, mesmo que pequena, a tendência é que os detritos comuns do esgoto doméstico, ao se depararem com essa obstrução, sejam acumulados paulatinamente, até obstruir toda a seção da tubulação, prolongando o assoreamento por um longo trecho à montante daquele onde está localizada a obstrução.

A partir das tabelas síntese, foram elaboradas as Tabelas 2 e 3.

As companhias de saneamento no Brasil basearam seus procedimentos

Tabela I - Tabela síntese típica; contendo dados do processo industrial, características dos efluentes gerados e manutenções realizadas

\begin{tabular}{|c|c|c|c|c|c|}
\hline \multicolumn{6}{|c|}{ Dados do processo industrial } \\
\hline Produto fabricado & Matéria prima & Produtos auxiliares & $\begin{array}{l}\text { Origem dos } \\
\text { efluentes }\end{array}$ & $\begin{array}{l}\text { Vazão doméstica } \\
\left(\mathrm{m}^{3} / \mathrm{dia}\right)\end{array}$ & $\begin{array}{l}\text { Vazão industrial } \\
\qquad\left(\mathrm{m}^{3} / \mathrm{dia}\right)\end{array}$ \\
\hline $\begin{array}{l}\text { Carpetes } \\
\text { tapetes }\end{array}$ & $\begin{array}{l}\text { poliamida } \\
\text { polipropileno }\end{array}$ & $\begin{array}{l}\text { corantes têxteis } \\
\text { ácido acético } \\
\text { amoníaco }\end{array}$ & $\begin{array}{l}\text { provenientes da } \\
\text { tinturaria } \\
\text { purga da caldeira } \\
\text { tingimento }\end{array}$ & 14,48 & 118,74 \\
\hline \multicolumn{6}{|c|}{ Características do efluente lançado na RCE } \\
\hline $\mathrm{pH}$ & $\begin{array}{l}\text { Óleos e Graxas } \\
\quad(\mathrm{mg} / \mathrm{L})\end{array}$ & $\begin{array}{c}\text { Sólidos } \\
\text { Sedimentáveis } \\
(\mathrm{mL} / \mathrm{L})\end{array}$ & $\begin{array}{c}\text { sólidos em } \\
\text { suspensão totais } \\
(\mathrm{mg} / \mathrm{L})\end{array}$ & $\begin{array}{l}\text { Sulfato } \\
(\mathrm{mg} / \mathrm{L})\end{array}$ & $\begin{array}{l}\text { Sulfeto } \\
(\mathrm{mg} / \mathrm{L})\end{array}$ \\
\hline 8,1 & 34 & 0,1 & 92 & 280 & 2 \\
\hline \multicolumn{6}{|c|}{ Manutençôes realizadas na RCE } \\
\hline \multicolumn{2}{|c|}{ No lançamento } & \multicolumn{2}{|c|}{ A montante do lançamento } & \multicolumn{2}{|c|}{ A jusante do lançamento } \\
\hline Serviço Executado & Data Execução & Serviço Executado & Data Execução & $\begin{array}{c}\text { Serviço } \\
\text { Executado }\end{array}$ & Data Execução \\
\hline $\begin{array}{l}\text { Desobstrução de } \\
\text { coletor esgotos }\end{array}$ & $13 / 06 / 02$ & $\begin{array}{c}\text { desobstrução de ramal } \\
\text { domiciliar }\end{array}$ & $09 / 12 / 02$ & $\begin{array}{l}\text { desobstrução de } \\
\text { ramal domiciliar }\end{array}$ & $28 / 10 / 02$ \\
\hline $\begin{array}{l}\text { Desobstrução de } \\
\text { ramal domiciliar }\end{array}$ & $14 / 06 / 02$ & $\begin{array}{c}\text { desobstrução de ramal } \\
\text { domiciliar }\end{array}$ & $19 / 03 / 03$ & $\begin{array}{l}\text { desobstrução de } \\
\text { coletor esgotos }\end{array}$ & $18 / 12 / 02$ \\
\hline
\end{tabular}


Tabela 2 - Empresas que atendem o Artigo 19A nos parâmetros óleos e graxas e sólidos sedimentáveis, freqüência de manutenções realizadas na RCE

\begin{tabular}{ccccccc}
\hline $\begin{array}{c}\text { No da } \\
\text { empresa }\end{array}$ & Ramo de Atividade & $\begin{array}{c}\text { OG } \\
(\mathrm{mg} / \mathrm{L})\end{array}$ & $\begin{array}{c}\text { Ssed } \\
(\mathrm{mg} / \mathrm{L})\end{array}$ & $\begin{array}{c}\text { SST } \\
(\mathrm{mg} / \mathrm{L})\end{array}$ & $\begin{array}{c}\text { Vazão } \\
\left(\mathrm{m}^{3} / \mathrm{dia}\right)\end{array}$ & $\begin{array}{c}\text { Freqüência de } \\
\text { manutençóes na } \\
\text { RCE }\end{array}$ \\
\hline 94 & Alimentícia & 25 & 5 & 670 & 7,07 & $\begin{array}{c}\text { Mensal } \\
\text { ¿ }\end{array}$ \\
5 & Galvanoplastia & 2 & 0,5 & 51 & 3,80 & Anual \\
6 & Galvanoplastia & 10 & 0,1 & 45 & 9,50 & Mensal \\
13 & Galvanoplastia & 2 & 0,2 & 94 & 6,05 & Bimestral \\
20 & Galvanoplastia & 2 & 0,1 & 112 & 16,61 & Semestral \\
114 & Galvanoplastia & 2 & 2 & 240 & 10,20 & Trimestral \\
126 & Gráfica & 92 & 0,1 & 20 & 15,53 & Mensal \\
128 & Gráfica & 2 & 0,4 & 76 & 136,00 & Bimestral \\
1 & Metalúrgica & 35 & 1 & 82 & 3,00 & Mensal \\
121 & Metalúrgica & 10 & 0,1 & 14 & 5,77 & Trimestral \\
7 & Têxtil & 34 & 0,1 & 92 & 118,74 & Semestral \\
\hline
\end{tabular}

Nota: OG - óleos e graxas; Ssed - sólidos sedimentáveis; SST (sólidos em suspensão totais)

Tabela 3 - Empresas que não atendem o Artigo I9A nos parâmetros óleos e graxas ou sólidos sedimentáveis, freqüência de manutenções realizadas na RCE

\begin{tabular}{ccccccc}
\hline $\begin{array}{c}\text { No da } \\
\text { empresa }\end{array}$ & Ramo de Atividade & $\begin{array}{c}\text { OG } \\
(\mathrm{mg} / \mathrm{L})\end{array}$ & $\begin{array}{c}\text { Ssed } \\
(\mathrm{mg} / \mathrm{L})\end{array}$ & $\begin{array}{c}\text { SST } \\
(\mathrm{mg} / \mathrm{L})\end{array}$ & $\begin{array}{c}\text { Vazão } \\
\left(\mathrm{m}^{3} / \mathrm{dia}\right)\end{array}$ & $\begin{array}{c}\text { Freqüência de } \\
\text { manutençóes na } \\
\text { RCE }\end{array}$ \\
\hline 17 & Alimentícia & 543 & 4,5 & 1250 & 181,96 & Mensal \\
52 & Alimentícia & 3500 & 7 & 1670 & 2,91 & Mensal \\
57 & Alimentícia & 210 & 9,5 & 335 & 82,20 & Mensal \\
49 & Metalúrgica & 276 & 0,2 & 460 & 0,16 & Trimestral \\
80 & Metalúrgica & 2280 & 1,6 & - & 22,51 & Semestral \\
118 & Metalúrgica & 740 & 0,1 & 26 & 11,77 & Mensal \\
78 & Plástica & 562 & 0,1 & 255 & $\tilde{n}$ informado & Trimestral \\
79 & Têxtil & 166 & 0,1 & 45 & 73,80 & Bimestral \\
109 & Têxtil & 1090 & 0,1 & 2 & 22,04 & Mensal \\
\hline
\end{tabular}

Nota: OG - óleos e graxas; Ssed - sólidos sedimentáveis; SST (sólidos em suspensão totais)

de aceitação de ENDs no SES apenas no atendimento à norma NBR 9800 (ABNT, 1987), a qual estabelece limites para lançamento de óleos e graxas de $150 \mathrm{mg} / \mathrm{L}$ e sólidos sedimentáveis de $20 \mathrm{~mL} / \mathrm{L}$, valores idênticos aos limites estabelecidos pelo artigo 19A do Decreto 15.425/80. Para exemplificar tal prática, descreve-se, a seguir, o procedimento adotado por uma companhia de saneamento de uma grande metrópole: "No momento que uma empresa solicita o lançamento de seus efluentes na RCE, técnicos da companhia de saneamento visitam o local e preenchem um questionário, onde constam os dados cadastrais da empresa, matéria(s) prima(s) utilizada(s), produto(s) fabricado(s) e vazão baseada no consumo de água fornecido pela companhia. Após a aquisição dos dados básicos, é apresentado ao cliente, o procedimento de cobrança por lançamento de efluentes com características não domésticas e é entregue um relatório, orientando-o para a realização de uma autocaracterização, caso o mesmo não aceite a cobrança por ramo de atividade. Fica a critério da área técnica, a realização ou não de uma coleta para avaliar se o efluente atende ou não aos limites estabelecidos na Norma”. No caso da empresa optar por autocaracterização para avaliar seu efluente, técnicos da companhia de saneamento acompanham a coleta, que é realizada de forma pontual, procedimento que em muitos casos não oferece uma representatividade do lançamento real. Quando os técnicos da companhia de saneamento decidem realizar uma caracterização do efluente, a coleta segue o mesmo procedimento da autocaracterização. Os dados de caracterização constantes das tabelas 2 e 3 foram obtidos através 
desse procedimento: amostra simples e pontual. Após a caracterização dos efluentes, as concentrações dos parâmetros são comparadas com os limites estabelecidos na norma. No entanto, outros elementos e compostos que não foram contemplados na mesma, mas que constam como produto auxiliar ou matéria prima da indústria ou serviço, podem provocar, por exemplo, obstruções, como no caso de fibras. Além disso, não se avaliam as condições da RCE que receberá os ENDs, ou seja, o material, a idade, a declividade, as contribuições de montante e jusante ao lançamento, etc.

A Tabela 2 apresenta as empresas que possuem pré-tratamento que enquadram seus efluentes na legislação no que se refere às concentrações de óleos e graxas e sólidos sedimentáveis, e portanto, segundo os critérios brasileiros atuais de recebimento de ENDs (CETESB, 1995; COPASA, 2002; CEARÁ, 2002), podem ser lançados no SES, sem causar problemas de incrustação. No entanto, a pesquisa realizada nos registros de manutenções ocorridas entre os anos de 2002 e 2005 nas RCEs que recebem tais efluentes, demonstra que os impactos de tais lançamentos foram expressivos, pois em muitas, a freqüência de manutenções é atípica. Embora segundo Tsutiya \& Além Sobrinho (2000), a rede coletora de esgotos deva ser projetada para ter uma declividade mínima que garanta uma velocidade de escoamento que arraste os resíduos comuns existentes nos esgotos domésticos, minimizando a freqüência de manutenções, normalmente, no projeto, não se avalia os ENDs.

A seguir, serão discutidos os dados de cada um dos ramos de atividade das empresas constantes na Tabela 2.

Os efluentes de indústrias alimentícias têm como principais características, concentrações elevadas de óleos e graxas. O pré-tratamento, normalmente adotado nesse ramo de atividade, são as caixas de gordura. Dependendo da vazão do efluente, tem-se uma capacidade mínima da unidade e uma freqüência mínima de limpeza que deve ser realizada, antes que alguma das seguintes condições ocorra (Sydney Water Corportation, 2004):

- A espessura da camada superficial, composta de óleos, graxas e materiais flutuantes, seja maior ou igual a $10 \%$ da profundidade total da caixa;
- A espessura da camada de sólidos no fundo da caixa seja maior ou igual a $20 \%$ da profundidade total da caixa;

- O fundo da caixa apresente uma camada de sólidos maior que $400 \mathrm{~mm}$;

- A somatória das espessuras das camadas superficial e de fundo seja maior que $25 \%$ da profundidade da caixa.

Uma capacidade insuficiente ou o não cumprimento das limpezas periódicas compromete a eficiência desse processo de tratamento, o que significa uma passagem direta dos óleos e graxas para a RCE. Observa-se, pelas manutençōes realizadas na RCE, que este fato pode estar ocorrendo no lançamento dessa empresa e o mesmo se expande para as demais nessas mesmas condiçôes, pois nos critérios atuais de recebimento, não está prevista a apresentação do projeto de dimensionamento da caixa de gordura para análise e nem a freqüência de limpeza no contrato de recebimento de indústrias alimentícias, como faz, por exemplo, a Sydney Water, concessionária de saneamento de Sydney, Austrália. Medidas simples assim poderão minimizar significativamente as manutenções nas RCEs que recebem esse ramo de atividade e diminuir os custos de coleta e transporte de esgotos.

A Figura 1 mostra os ciclos de manutençōes semestrais realizados na RCE para as empresas do ramo da indústria alimentícia, constantes das Tabelas 2 e 3 .

Para analisar os casos das galvanoplastias apresentadas na Tabela 2, realizou-se uma pesquisa sobre os efluentes destas categorias industriais, que além de possuírem concentrações elevadas de metais pesados, podem apresentar concentrações de sulfato de

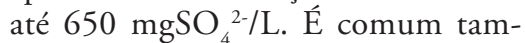
bém encontrar valores de $\mathrm{pH}$ de 1,6 e concentraçôes de óleos e graxas de até 868 mg/L (CETESB, 1990). Os efluentes desta atividade, muitas vezes, são neutralizados com cal, o que ocasiona a precipitação do sulfato de cálcio, que é pouco solúvel (WEF, 1994). Se esse material de alguma forma for carreado para a RCE, a probabilidade de ocorrer incrustação é iminente.

Essa análise mostra que esses efluentes não representam apenas um problema ambiental, que afeta as características do efluente final e do lodo das ETEs, mas também um problema no sistema de coleta e transporte de esgotos, que é um patrimônio público. Sendo assim, como critérios de recebimento de galvanoplastias no SES deveriam ser incluídos:

- Caracterização dos efluentes bruto e tratado;

- Análise do material da RCE que irá receber tais efluentes;

- Substâncias utilizadas no prétratamento, principalmente na neutralização do $\mathrm{pH}$.

Aos critérios citados anteriormente, deve-se acrescentar a observação em relação à matéria prima e aos produtos auxiliares, pois existem perdas de matéria no processo, as quais se dão pelo arraste de um tanque de banho a outro, podendo atingir uma perda de até $40 \mathrm{~L} / \mathrm{m}^{2}$ (CETESB, 1990). Mesmo que haja um bom sistema de drenagem dos respingos oriundos do arraste, muito provavelmente, parte é encaminhada para o sistema de esgotos antes de

Manutenção na RCE - Indústrias Alimentícias

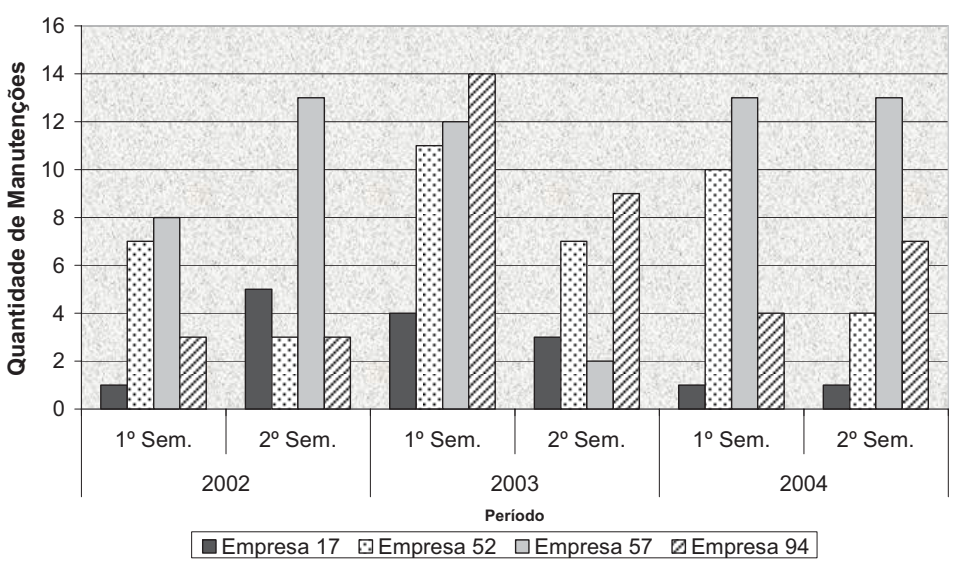

Figura I - Manutenções na RCE devido ao lançamento de indústrias alimentícias 
passar pelo pré-tratamento, conforme mostra a Figura 2. Quando se faz uma lavagem geral das instalações, a unidade de pré-tratamento, muitas vezes, não está preparada para tratar uma vazão tão elevada, sendo então encaminhada diretamente para a RCE, carreando os materiais que respingaram no piso. Por isso, a importância do conhecimento das matérias primas para saber quais são os materiais flutuantes e os que sedimentam, pois estes estão diretamente relacionados com as interferências na RCE.

A Figura 3 mostra os ciclos de manutençōes semestrais realizados na RCE para as empresas do ramo de galvanoplastias constantes das Tabelas 2 e 3 .

As indústrias gráficas, indicadas na Tabela 2, principalmente a empresa 128, por se tratar de uma gráfica de grande porte, apesar de não apresentar concentrações elevadas de materiais solúveis em $\mathrm{n}$-hexano e sólidos em suspensão totais, possui efluente com concentrações de sulfato e sulfeto acima dos parâmetros estabelecidos pelo Artigo 19A. Para analisar as interferências que esses parâmetros causaram no SES, foram avaliadas as manutençōes ocorridas entre os anos de 2002 e 2005 e constatou-se o seguinte:

- Ano de 2002: Houve somente uma campanha de manutenções no $1^{\circ}$ semestre, incluindo duas desobstruções de coletor;

- Ano de 2003: Houve uma campanha no $1^{\mathrm{o}}$ semestre, incluindo duas lavagens de rede coletora e apenas um conserto de coletor no segundo semestre.

- Ano de 2004: manutenções mensais no $1^{\circ}$ semestre até o momento em que foi realizado um televisionamento de rede coletora de esgotos por circuito fechado e constatou-se uma incrustação, próximo ao lançamento (Figura 4).

O processo de incrustação observado pode ser conseqüência do lançamento de elevadas concentrações de sulfato, que associado com outras substâncias, formam precipitados de baixa solubilidade, como o sulfato de íons divalentes (cálcio, magnésio, bário, etc).

A empresa 7 , apresentada na Tabela 2, é uma industria têxtil de grande porte, que normalmente sofre uma fiscalização mais efetiva por parte da agência ambiental e da concessionária de saneamento. Segundo a USEPA (EPA, 2005), é comum empresas desse

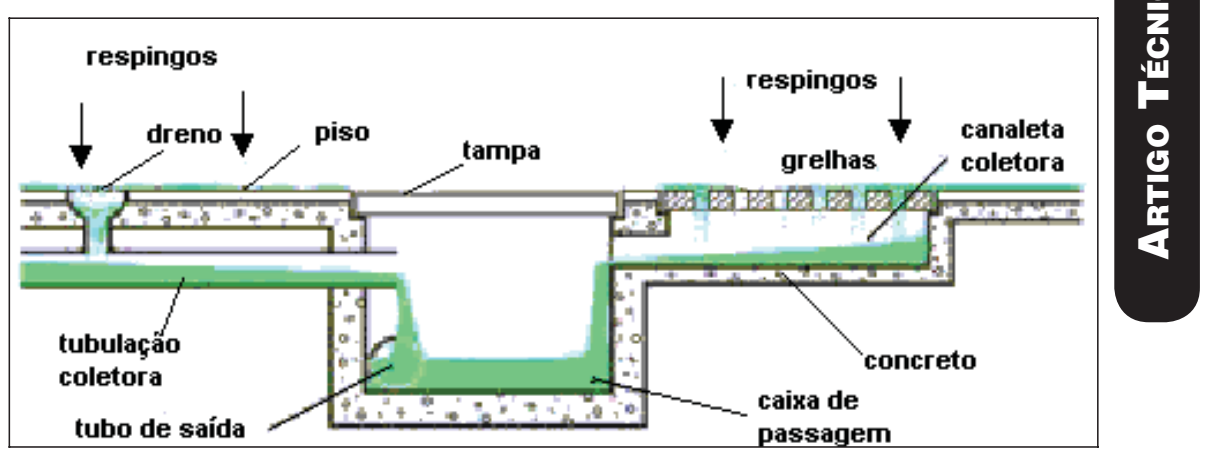

Figura 2 - Representação do sistema de drenagem dos respingos do arraste dos banhos em galvanoplastias (CETESB, 1990)
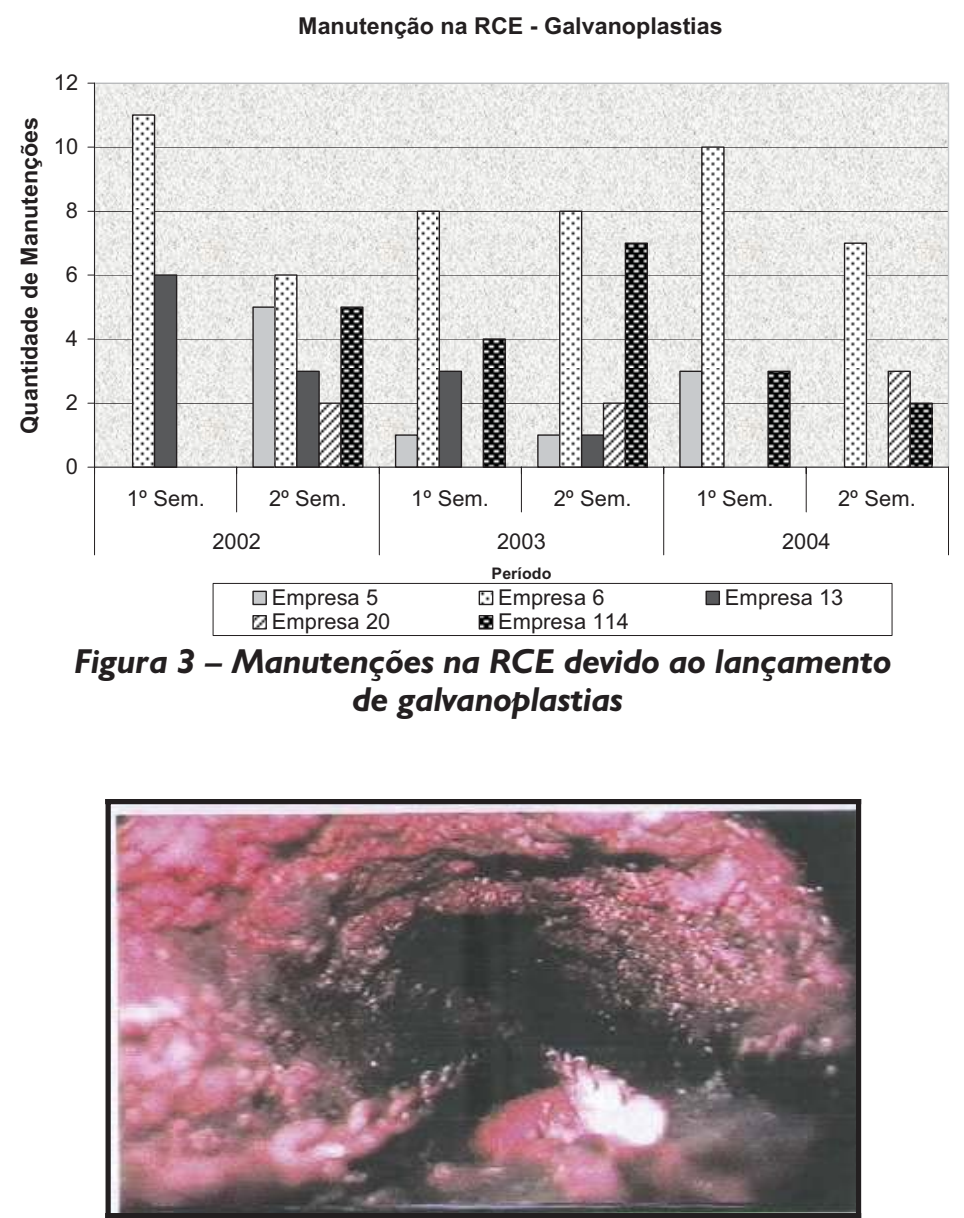

Figura 4 - Incrustação na RCE que recebe a empresa 128 (SABESP, 2004)

ramo de atividade apresentarem óleos e graxas nos efluentes. Essa empresa possui um pré-tratamento eficiente, demonstrado pelos resultados das concentraçôes de materiais solúveis em n-hexano e sulfatos. É fácil constatar essa eficiência, através da freqüência de manutençôes realizadas na RCE (exceto o $1^{\circ}$ semestre de 2004, que apresentou comportamento atípico). Verifica-se, também, a importância da fiscalização através da comparação dos dados da empresa 7 com os resultados mostrados na Tabela 3, que traz o caso de duas indústrias têxteis, que lançam vazões inferiores à da indústria em questão e que, no entanto, apresentam concentrações de materiais solúveis em n-hexano acima dos limites da legislação. Estes lançamentos provocaram freqüentes manutenções na RCE, como mostra o gráfico comparativo da Figura 5.

A respeito das metalúrgicas indicadas na Tabela 2, pode-se observar que 
são empresas de pequeno porte, com vazão média de $4 \mathrm{~m}^{3} /$ dia e que os parâmetros determinados em seus efluentes estão de acordo com a legislação. Essas empresas possuem pré-tratamento dos efluentes gerados, porém não há uma fiscalização efetiva, nem tampouco uma obrigatoriedade de apresentação de laudos de automonitoramento. Essas duas medidas simples de controle poderiam evitar o inconveniente das constantes manutençôes realizadas na RCE. A seguir, é apresentado um resumo das mesmas:

- Ano de 2002: No primeiro semestre, foram realizadas 6 desobstruções de coletor de esgotos e no segundo, duas limpezas de PV, duas desobstruções e um conserto de coletor. Este pode ter sido conseqüência das constantes obstruçôes, pois como a RCE desse logradouro é de manilha de barro, se as juntas não forem bem executadas, quando há uma obstrução, a tubulação trabalha em seção plena, e essa condição faz com que ocorra vazamento nas juntas, provocando uma erosão em torno da tubulação e como conseqüência, o seu arriamento. Uma segunda hipótese seria a necessidade de troca de algum trecho devido a impossibilidade de desobstrução.

- Em 2003: Foram registradas duas desobstruçóes de coletor de esgotos e uma limpeza de PV no primeiro semestre e no segundo, a freqüência de manutenções volta a ser mensal, sendo registradas cinco desobstruções de coletor e duas limpezas de PV.

- Em 2004: Nesse ano, repetiu-se o ciclo apresentado em 2003, sendo registradas três desobstruçóes de coletor no primeiro semestre e seis no segundo, além de duas limpezas de PV.

- Em 2005: Mais uma vez, repetiu-se o ciclo observado nos primeiros semestres de 2003 e 2004, onde foram registradas três desobstruções de coletor e duas limpezas de PV.

A Figura 6 apresenta os ciclos de manutenção graficamente para as metalúrgicas apresentadas nas Tabelas 2 e 3, inclusive para o caso da empresa 1.

$\mathrm{O}$ ciclo de manutençôes apresentado deixa claro o efeito que esse ramo de atividade exerce sobre o sistema de coleta e transporte de esgotos. Segundo a USEPA (EPA, 2005), as metalúrgicas têm como principais características em seus efluentes, elevadas concentraçóes de materiais solúveis em n-hexano. Caixas separadoras de óleo, normalmente,

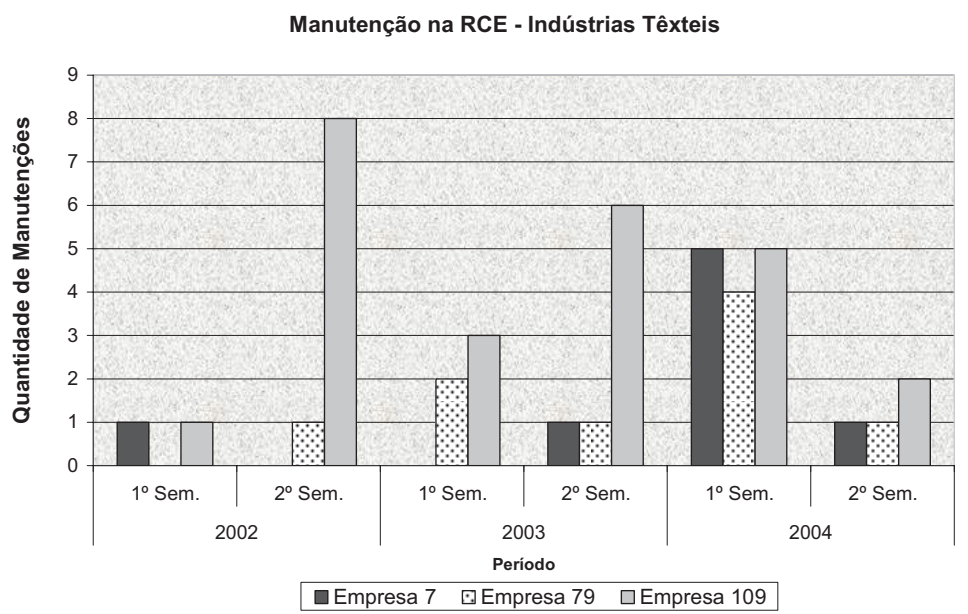

Figura 5 - Manutenções na RCE devido ao lançamento de indústrias têxteis

Manutenção na RCE - Metalúrgicas

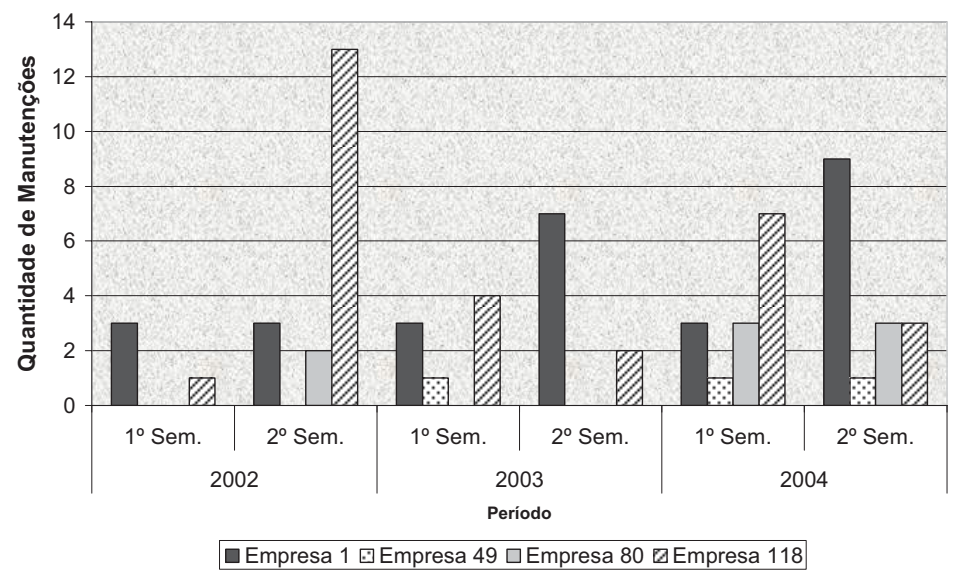

Figura 6 - Manutenções na RCE devido aos problemas provocados pelo lançamento de metalúrgicas

são utilizadas como pré-tratamento (WEF, 1994). Entretanto, apenas a existência destas unidades não garante a proteção do sistema de coleta e transporte de esgotos. Qualquer empresa que opte por esse tipo de tratamento e não realize as devidas manutenções, pode prejudicar mais o SES do que se não o tivesse implantado, uma vez que estará lançando um efluente mais concentrado de óleos e graxas.

\section{Explosividade e inflamabilidade no SES}

A legislação vigente no Estado de São Paulo para o lançamento de END no SES prevê ausência de solventes e substâncias explosivas e inflamáveis em lançamentos de qualquer fonte poluidora, no entanto, em muitos laudos pesquisados foi verificada a presença de pequenas concentraçôes de benzeno, tolueno, etilbenzeno e xileno (BTEX), únicos parâmetros analisados pelas concessionárias de saneamento para atender tal exigência legal, em diversos ramos de atividade. Para certificar se esses lançamentos poderiam estar propiciando uma atmosfera explosiva no interior do SES, foram realizadas medições do limite de explosividade em 27 pontos.

Dos resultados obtidos, destacamse três pontos, nos quais as medições apresentaram um limite inferior de explosividade acima de $10 \%$, o que representa um risco eminente de explosão no caso de haver alguma fonte de ignição (CETESB, 2004). Deve-se ressaltar, no entanto, que nos pontos que apresentaram esses valores, os PVs encontravamse obstruídos pela presença de óleos e graxas. Dessa forma, há uma hipótese de que essa obstrução provocou um acúmulo de gases inflamáveis e explosivos num espaço confinado e sem ventilação, pois não foram observados altos limites de explosividade nos demais pontos, mesmo naqueles nos quais estavam 
sendo lançados efluentes de empresas com concentrações de solventes entre 30 e $3.000 \mu \mathrm{g} / \mathrm{L}$. A característica principal destes lançamentos é em relação ao regime de escoamento na RCE, ou seja, nestes pontos não havia obstrução.Vale ressaltar, no entanto, que, atualmente, o sistema de coleta e transporte de esgotos ainda não trabalha a carga plena e que, no futuro, estas descargas poderão provocar explosão.

Três pontos, além de apresentarem LIE de $1 \%$, indicaram baixa concentração de oxigênio - em torno de $18 \%$ - o que pode significar que estava ocorrendo uma troca de gases na atmosfera do PV
(EPA, 1995 a e b). Nesses pontos e em um ponto, que apresentou um LIE de $20 \%$, podê-se associar os resultados com as características dos efluentes lançados, o que justifica a necessidade do monitoramento desse parâmetro pelas companhias de saneamento, embasados numa legislação na qual constem procedimentos claros de controle e não apenas a exigência de ausência de substâncias explosivas e inflamáveis nos efluentes lançados no SES (CETESB, 1995).

Os resultados dos relatórios dos atendimentos de emergência realizados pelo setor de emergências químicas da CETESB são apresentados na Tabela $4 \mathrm{e}$ os limites de explosividade demonstram a importância da elaboração de um procedimento para o monitoramento do LIE no SES em áreas onde há concentração de postos de combustíveis, ou até mesmo a instalação de equipamentos on-line pelas companhias de saneamento, medida essa que garantirá não somente a integridade do sistema de coleta e saúde dos operadores, como também dos usuários do SES.

O termo passivo ambiental, que aparece naTabela 4, refere-se à existência de resíduos ou produtos num determinado estabelecimento, dispostos de forma inadequada ambientalmente.

Tabela 4 - Resultado dos atendimentos de emergência realizados pelo setor de emergência da CETESB entre 1998 e 2004 na RMSP

\begin{tabular}{|c|c|c|c|c|c|}
\hline Causa & Ocorrência & Data & $\begin{array}{c}\text { Produto } \\
\text { identificado }\end{array}$ & $\begin{array}{l}\text { LIE } \\
(\%)\end{array}$ & Observações \\
\hline Flutuação de tanque & $\begin{array}{l}\text { Odor de combustível } \\
\text { em rede de esgoto }\end{array}$ & $08 / 01 / 98$ & Gasolina & 30 & - \\
\hline Furo em tanque & $\begin{array}{l}\text { Odor de combustível } \\
\text { em rede de esgoto }\end{array}$ & $17 / 01 / 98$ & Gasolina & 100 & - \\
\hline Furo em linha & $\begin{array}{l}\text { Odor de combustível } \\
\text { em rede de esgoto }\end{array}$ & $28 / 02 / 98$ & Gasolina & - & - \\
\hline Furo em linha & $\begin{array}{l}\text { Odor de combustível } \\
\text { em rede de esgoto }\end{array}$ & $06 / 03 / 98$ & Gasolina & 60 & - \\
\hline Passivo ambiental & $\begin{array}{c}\text { Presença de resíduos } \\
\text { oleosos em PV }\end{array}$ & $26 / 11 / 98$ & Resíduos oleosos & 60 & $\begin{array}{l}\text { Por ocasião de chuvas } \\
\text { houve extravasamento de } \\
\text { resíduos oleosos para a RCE }\end{array}$ \\
\hline Furo em linha & $\begin{array}{l}\text { Odor de combustível } \\
\text { em vala da SABESP }\end{array}$ & $17 / 08 / 99$ & Gasolina & 100 & - \\
\hline Passivo ambiental & $\begin{array}{l}\text { Odor de combustível } \\
\text { em rede de esgoto }\end{array}$ & $17 / 08 / 99$ & Gasolina & 100 & - \\
\hline Furo em tanque & $\begin{array}{l}\text { Odor de combustível } \\
\text { em rede de esgoto }\end{array}$ & 03/09/99 & Gasolina & 100 & - \\
\hline Passivo ambiental & $\begin{array}{l}\text { Odor em rede de } \\
\text { esgoto }\end{array}$ & $17 / 02 / 00$ & Gasolina & - & - \\
\hline Descarte de produto & $\begin{array}{c}\text { Presença de } \\
\text { combustível na rede } \\
\text { de esgoto }\end{array}$ & $02 / 01 / 01$ & Óleo Diesel & - & $\begin{array}{l}\text { Lançamento de vários } \\
\text { tambores dew } 200 \text { litros na } \\
\text { rede }\end{array}$ \\
\hline $\begin{array}{l}\text { Operação inadequada } \\
\text { - caixa separadora de } \\
\text { óleo }\end{array}$ & $\begin{array}{l}\text { Odor de combustível } \\
\text { na rede de esgotos }\end{array}$ & $23 / 11 / 01$ & Gasolina & 60 & $\begin{array}{l}\text { Extravasão da caixa } \\
\text { separadora na rede }\end{array}$ \\
\hline $\begin{array}{l}\text { Extravasamento de } \\
\text { tanque }\end{array}$ & $\begin{array}{l}\text { Odor de combustível } \\
\text { na rede de esgoto }\end{array}$ & $03 / 03 / 02$ & Gasolina & 10 & $\begin{array}{c}\text { Transbordamento de } \\
\text { gasolina }\end{array}$ \\
\hline Furo em tanque & $\begin{array}{l}\text { Odor de combustível } \\
\text { em rede de esgotos }\end{array}$ & $29 / 05 / 02$ & Gasolina & 24 & $\begin{array}{l}\text { Vazamento na tubulação da } \\
\text { bomba }\end{array}$ \\
\hline Passivo ambiental & $\begin{array}{l}\text { Presença de } \\
\text { combustível }\end{array}$ & $21 / 06 / 02$ & Óleo Diesel & 100 & Em coletor tronco \\
\hline Passivo ambiental & $\begin{array}{l}\text { Presença de odor em } \\
\text { rede de esgotos }\end{array}$ & $12 / 01 / 04$ & - & - & $\begin{array}{l}\text { Lançamento de excedente } \\
\text { da caixa separadora em rede }\end{array}$ \\
\hline
\end{tabular}

Fonte: CETESB (2004) 


\section{Avaliação das concentrações de sulfeto nos esgotos do SES}

Dos dados das 49 coletas realizadas no SES em bacias de esgotamento predominantemente residenciais, observou-se que o sulfeto, limitado pelo Artigo 19A do Decreto Estadual 15.425/80 (CETESB, 1995) em $1 \mathrm{mgS}^{2-} / \mathrm{L}$, apresentou concentrações acima deste valor em mais de 50\% das amostras. Esses resultados mostram a necessidade de uma revisão do limite estabelecido para esse parâmetro, pois se os esgotos domésticos que fluem no SES já apresentam uma concentração maior que $1 \mathrm{mgS} S^{2-} / \mathrm{L}$, limitá-la nesse valor para lançamento dos ENDs é uma incoerência. Além disso, os interceptores e coletores, onde foram realizadas as coletas, são de concreto armado e estão em funcionamento há mais de 10 anos, sem nenhuma manutenção do tipo: troca de trecho devido a corrosão.

\section{CONCLUSÕES}

Dos resultados obtidos no presente trabalho, conclui-se que:

- Efluentes não domésticos lançados no SES contendo sólidos sedimentáveis e concentraçôes de óleos e graxas (materiais solúveis em $\mathrm{n}$-hexano) abaixo dos limites estabelecidos no Artigo 19A do Decreto 15425/80 causaram obstrução e incrustração no sistema de esgotamento sanitário;

- Mais de 50\% das amostras de esgoto predominantemente doméstico, coletadas no sistema de esgotamento sanitário e avaliadas no presente trabalho, apresentaram concentrações de sulfeto acima do limite estabelecido no Artigo 19A do Decreto 15425/80, indicando que é necessário um novo limite para este parâmetro;

- Determinações das concentrações de sulfeto realizadas em coletores tronco e interceptores da Região Metropolitana de São Paulo indicaram

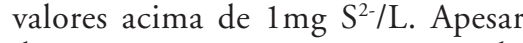
destas concentrações, não têm sido detectados problemas de corrosão nos últimos 10 anos;

- Efluentes não domésticos lançados com concentraçóes de até $3000 \mu \mathrm{g} / \mathrm{L}$ de benzeno, tolueno, etil benzeno e xileno não apresentaram valores de limite de explosividade que propiciasse uma atmosfera explosiva no interior do sistema de esgotamento sanitário;
- Postos de combustíveis devem ser considerados em programas de recebimento de efluentes não domésticos em sistema público de esgotos;

- A observância das matérias primas, dos produtos auxiliares e fluxogramas do processo produtivo deve ser realizada na avaliação da possibilidade de recebimento dos efluentes não domésticos no sistema de esgotamento sanitário;

- O órgão responsável pelo sistema de esgotamento sanitário deve levar em consideração as condiçôes operacionais das unidades de pré-tratamento no monitoramento dos efluentes não domésticos;

- Nos órgãos responsáveis pelo sistema de esgotamento sanitário, deve haver comunicação entre as áreas de manutenção e controle de recebimento de efluentes não domésticos, de tal forma a uma subsidiar a outra com informações técnicas pertinentes ao bom funcionamento do sistema;

- Recomenda-se que o órgão responsável pelo sistema de esgotamento sanitário realize o monitoramento do limite inferior de explosividade RCE;

- Os critérios atuais de recebimento de efluentes não domésticos no sistema de esgotamento sanitário, no que se refere às interferências físicas e operacionais, não são eficazes.

\section{REFERÊNCIAS}

AMERICAN PUBLIC HEALTH ASSOCIATION (APHA); AMERICAN WATER WORKS ASSOCIATION (AWWA); WATER ENVIRONMENTAL FEDERATION (WEF). Standard Methods for the Examination of water and wastewater. Washington: American Public Health Association. 1998.

ASSOCIAÇÃO BRASILEIRA DE NORMAS TÉCNICAS (ABNT). NBR. 9800. Critérios para lançamento de efluentes líquidos industriais no sistema coletor público de esgoto sanitário. Brasil: ABNT, 1987.

CEARÁ. SUPERINTENDÊNCIA ESTADUAL DO MEIO AMBIENTE (SEMACE). Portaria SEMACE N. ${ }^{\circ} 154 / 2002$. Fortaleza. 22 de jul. 2002.

COMPANHIADESANEAMENTO DEMINAS GERAIS (COPASA). Belo Horizonte Programa de recebimento e controle de efluentes para usuários não domésticos. 2002 Disponível em: http://www.copasa. com.br Acesso em 25 de fev 2005.

COMPANHIA DE TECNOLOGIA DE SANEAMENTO AMBIENTAL (CETESB). Nota técnica sobre tecnologia de controle: Galvanoplastias. São Paulo: CETESB, 1990.

COMPANHIA DE TECNOLOGIA DE SANEAMENTO AMBIENTAL (CETESB). D $e$ creto Estadual 15.425/80. In: Legislação Estadual, Série Documentos. São Paulo: CETESB, 1995. DO ESTADO DE SÃO PAULO (SABESP).
Relatório de inspeção por circuito fechado de TV. São Paulo. SABESP. (relatório interno SABESP). 2004

COMPANHIA DE TECNOLOGIA DE SANEAMENTO AMBIENTAL (CETESB). São Paulo. 2004. Atendimentos de emergência. Disponível em: www.cetesb.gov.br Acesso em 05 de jan. 2004

ENVIRONMENTAL PROTECTION AGENCY (EPA). Operation and maintenance of wastewater collection systems: A field study training program. 5 ed. California: EPA, v. 1. 1995a.

ENVIRONMENTAL PROTECTION AGENCY (EPA). Operation and maintenance of wastewater collection systems: A field study training program. 5 ed. California:EPA, v. 2 1995b.

ENVIRONMENTAL PROTECTION AGENCY (EPA). Report to congress on the discharge of hazardous wastes to publicly owned treatment works. Washington: EPA, 1986.

ENVIRONMENTALPROTECTIONAGENCY (EPA). Federal Register: Electronic Code of Federal Regulations; Part 420 iron and steel manufacturing point source category. Washington, 2005. Disponível em: http://www.epa.gov/guide/. Acesso em 02 de maio de 2005.

ESTADOS UNIDOS. Department of Health and Human Services Public Health Service. Agency for Toxic Substances and Disease Registry Draft. Interaction Profile For: Benzene, Toluene, Ethylbenzene, and Xylenes (BTEX). Public Comment Period Ends September 2, Atlanta 2002.

KIENOW, K. K.; KIENOW, K. E. Corrosion below Sewer Structures. Califórnia: Kienow Associates, Inc. Consult Civil and Environmental Engineeers in Redlands. 2005. Disponível em http://www.a-lok. com/CORROSIONBELOW.html. Acesso em 02 de fev. de 2005.

MORITA, D. M. Tratabilidade de águas residuárias contendo poluentes perigosos: estudo de caso. Tese (Doutorado). Universidade de São Paulo. Escola Politécnica. 4v. 1993.

SYDNEY WATER CORPORATION. Trade Waste Policy. Sydney, 2004. Disponível em http:// www.sydneywater.com.au/Publications/ 2004.

TSUTIYA, M. T.; ALEM SOBRINHO, P. Coleta e transporte de esgoto sanitário. 2. ed. São Paulo. Winner Graff. 2000.

WATER ENVIRONMENT FEDERATION. Pretreatment of industrial wastes: manual of practice -FD 3. Alexandria, Virginia: WEF. 1994.

Endereço para correspondência:
Irineu Delatorre Junior
Companhia de Saneamento
Básico do Estado de São Paulo
Divisão de Operação de Água
Rua Conselheiro Saraiva, 519
02037-02 I São Paulo - SP - Brasil
Tel.: (I I) 697I-4082
E-mail: idjunior@sabesp.com.br 